\title{
Epidemiology and Clinical Features of Obsessive- Compulsive Disorder During Pregnancy and Postpartum Period: A Review
}

\author{
Faruk Uguz', Medine Glynas Ayhan ${ }^{1}$
}

\section{ÖZET:}

Gebelik ve postpartum dönemde obsesif kompulsif bozuklug̃un epidemiyolojisi ve klinik özelikleri: Bir gözden geçirme

Bu makale obsesif kompulsif bozuklug̃un (OKB) gebelik ve postpartum dönemde epidemiyolojisi ve klinik özellikleri ile ilgili güncel literatürü gözden geçirmektedir. Konu ile ilgili bildiriler önemli sınırlılıklar ve farklı sonuçlara içermektedir. Bununla birlikte OKB'nin prevalans ve insidans oranları genel toplumda bildirilenlere göre bu iki dönemde daha yüksektir. Gebelik ve puerperiumda en sık obsesyonlar bulașma ve saldırganlık obsesyonlarıdır. Saldırganlık obsesyonları postpartum dönemdeki kadınlarda bu dönemde olmayan kadınlara göre daha sık gözlenmektedir. Sonuç olarak, gebelik ve postpartum dönemler OKB'nin ortaya çıkmasında riskli dönemler olarak görünmektedir. Dolayısıyla bu dönemde olan kadınlar OKB yönünden taranmalıdır.

Anahtar sözcükler: obsesif kompulsif bozukluk, kadın, gebelik, postpartum dönem

Journal of Mood Disorders 2011;1(4):178-86

\section{ABSTRACT:}

Epidemiology and clinical features of obsessivecompulsive disorder during pregnancy and postpartum period: a review

In this study we reviewed the current literature on the epidemiology and clinical features of obsessive-compulsive disorder (OCD) during pregnancy and postpartum period. The available reports on this topic have significant limitations and heterogenous methods. However, the prevalence and incidence rates of $O C D$ reported during these two reproductive periods are higher than the rates estimated in the general population. The most common obsessions in pregnancy and puerperium were contamination and aggressive obsessions. Aggressive obsessions are observed more frequently in postpartum women compared to non-postpartum women. Pregnancy and postpartum periods appear to be risk periods for new-onset $O C D$. For this reason, pregnant and postpartum women should be screened with respect to OCD.

Key words: obsessive-compulsive disorder, women, pregnancy, postpartum period

Journal of Mood Disorders 2011;1(4):178-86
${ }^{1} \mathrm{MD}$, Selcuk University, Meram Faculty of Medicine, Department of Psychiatry, Konya-Turkey

Yazısma Adresi / Address reprint requests to: Faruk Uguz, Selcuk University, Meram Faculty of Medicine, Department of Psychiatry, Konya-Turkey

Telefon / Phone: +90-332-223-6126

Elektronik posta adresi / E-mail address: farukuguz@gmail.com

Kabul tarihi / Date of acceptance: 19 Aralık 2011 / December 19, 2011

Bag̃ıntı beyanı: F.U., M.G.A.: Yazarlar bu makale ile ilgili olarak herhangi bir çıkar çatışması bildirmemișlerdir.

Declaration of interest:

F.U., M.G.A.: The authors reported no conflict of interest related to this article.

\section{INTRODUCTION}

Obsessive-compulsive disorder (OCD) is a relatively common psychiatric disorder with a lifetime prevalence rate of $0.8 \%$ to $3.2 \%$ in the community (1-6). In addition to its frequent occurence, it is an important health problem, because it leads to an impairment in the quality of life and functional status and to disabilities in occupational and social areas (7-9). Epidemiological studies suggest that OCD is observed more frequently in females compared to males (2,3,10-12). Moreover, the mean age of onset of OCD includes the childbearing years in women (12). These findings imply that reproductive events such as pregnancy and childbirth may be related to OCD in females.

Following the publication of several case reports and retrospective studies (13-17) suggesting that there is a relationship between postpartum period and pregnancy and the development of OCD, attention of researchers on this topic has been increasing.. In the past the studies mostly focused on depressive disorders in pregnancy and puerperium. Comprehensive investigations about OCD during these periods have been neglected untill recent years. Additionally, the available studies evidently used heterogenous methodologies. On the other hand, women with postpartum-onset OCD often experience obsessions about harming their baby, they may avoid their infants due to their fear of acting on such thoughts. For this reason, their symptoms often impair their ability to care for their infants. The presence of unwanted obsessional thoughts is distressing to the point that they give rise to depressive symptoms. 
Several questions arise to delineate the connections between OCD and pregnancy and postnatal period in clinical practice:

1. What are the prevalence and incidence of OCD during these periods?

2. Are pregnancy and puerperium the risk periods for the occurence of OCD?

3. What are the clinical features of pregnancy- and postpartum-onset OCD?

4. What are the risk factors for pregnancy- and postpartum-onset $\mathrm{OCD}$ ?

5. What is the course of any pre-existing OCD during these periods?

6. What is the course of pregnancy- and postpartumonset OCD?

The objective of this review was to answer the above questions except pathogenesis and treatment on the basis of the data available from published studies or case reports in the literature.

\section{PREVALENCE}

Based on the literature analyzed, the most common data on OCD in females during their reproductive periods seem to be regarding the prevalence of OCD in pregnancy and puerperium. Although prevalence of OCD during pregnancy has been reported to vary in the range of $0.2 \%$ $5.2 \%$ in the literature, the relatively consistent rates among the studies are between $1 \%$ to $3 \%$ (18-25). On the other hand, Chaudron and Nirodi (26) reported that $29 \%$ of 24 pregnant women who completed a structured clinical interview met the criteria for OCD. This proportion is much higher than prevalence rates reported in previous studies.

There are several potential reasons for the variability in the prevalence rates. Five different diagnostic instruments have used in the eight studies referred above which may have affected the prevalence rates. Another factor may be intrinsic differences between the populations where the studies were conducted. As reviewed by Fontenelle et al. (27), the prevalence rates of OCD may have fluctations of up to ten times among different communities. Obsessive-compulsive symptoms are more frequently seen in pregnant women. According to two recent studies, $10 \%$ to $25 \%$ of pregnant women have obsessive-compulsive symptoms $(28,29)$.
Because of the variability in the assessment times and diagnostic instruments, the prevalence rate of OCD in the postnatal period has been reported within a wide range of $0.7 \%$ to $9.0 \%$ (19,30-33). Wenzel et al. (2005) also found the rate of subsyndromal OCD to be $5.4 \%$ at eight weeks postpartum (30). Obsessive-compulsive symptoms were described in $14 \%-63.5 \%$ of postpartum women $(28,31,33)$. Additionally, the studies also suggest that most new parents experience intrusive thoughts about their infant, although these thoughts do not necessarily indicate OCD $(34,36,37)$.

In view of a deficiency in controlled studies, it is unclear whether pregnancy and puerperium increase the risk of development of OCD. However, when the available data were gathered, OCD seems to more prevalent in pregnant and postpartum women when compared to women in the general population (current prevalence rate of $0.1 \%-1.5 \%)(2,38,39)$. These findings may allow us to conclude that pregnancy and puerperium are risk periods for the development of OCD. This opinion is relatively well-supported by some epidemiological data provided from communities where studies in pregnant or postpartum women were carried out. For example, in a large sample study, it was found that $1.6 \%$ of Italian pregnant women displayed OCD (24), while this rate was estimated to be $0.6 \%-1.2 \%$ among women in the general Italian population $(40,41)$. The prevalence rate of OCD in a sample of pregnant women in Nigeria was reported to be $5.2 \%$ (22), which is very high compared to the 12 -month prevalence rate $(0.2 \%)$ reported in the Nigerian Survey of Mental Health (42). OCD found to be slightly higher among pregnant women compared to women in the general population $(3.5 \%$ vs $2.9 \%)$ in Turkey $(11,25)$. Similarly, the prevalence rate of OCD in postpartum women and in the general population was reported to be $9.0 \%$ and $0.1 \%$ respectively, in Brazil $(33,38)$.

The major weakness in most of the available studies is a lack of comparative control subjects. To date, only two studies with control group have been published in the literature. These studies suggested that the prevalence rate of OCD in pregnant and non-pregnant women was not significantly different. However, the small sample size was a considerable factor restricting interpretation of results of both studies. $(22,43)$.

Inadequacy in number of community-based studies is another limitation in the interpretation of the results. 
Recently, results of a comparative epidemiological study regarding psychiatric disorders during pregnancy and the postnatal period in the United States were published, but this report does not show any data about OCD (44). Similar to this study, controlled community-based investigations should be conducted to determine whether OCD is more prevalent in pregnancy and puerperium.

\section{INCIDENCE}

There are very few studies on the incidence of OCD during pregnancy and the postpartum period. Some authors noted that $0.5 \%$ to $0.7 \%$ of pregnant women reported a new onset of OCD during their gestation $(25,45)$. However, these data are based on pregnant womens' retrospective recall of the onset time of OCD.

Retrospective studies carried out on female outpatients with OCD suggest that pregnancy is associated with the onset of OCD in a considerable proportion of female patients $(5.7 \%-39 \%)$ who had been pregnant at least once (13,46-49). Moreover, Neziroglu et al. (13) found that pregnancy was more associated with the onset of OCD than other life events. Additionally, there are several case reports supporting these findings $(16,17,50)$.

Two prospective studies indicated that $1.7 \%$ to $4.0 \%$ of mothers had new-onset of OCD after childbirth $(45,51)$. These rates are consistent with results of cross-sectional studies. Wenzel et al.found that 4 (2.7\%) of 147 postpartum women had OCD which began in $2.0 \%$ of the women during the puerperium (30). Recently, Zambaldi et al. (33) have reported an new-onset OCD rate of $2.3 \%$ at the postpartum period. In contrast, Chaudron and Nirodi (26) reported in a prospective study with small sample size that the incidence rate of OCD was $12.5 \%$ in the postpartum period. The studies also suggest that OCD may begin after childbirth in $25 \%$ to $75 \%$ of postpartum women with OCD $(30,33,52)$.

When childbearing female patients with OCD attending a clinical setting were retrospectively assessed, the postpartum period was associated with an onset of OCD up to $50 \%(46-49,53)$. In a study by Maina et al. (53), when compared to healthy subjects, female OCD patients with children more frequently reported childbirth to be a precipitating event for the onset of OCD. In addition, more data about postpartum-onset OCD are available when compared with pregnancy-induced OCD $(14,15,54)$.
Thus, the incidence rates suggest that women have increased risk for the occurence of OCD in the pregnancy and postpartum period. This risk seems to be higher in new mothers compared to pregnant women. However, the present data have considerable limitations. First, the number of the incidence studies is very limited. Second, there are no reported prospective studies in which pregnant women were followed from the beginning of pregnancy to the delivery period. More importantly, none of the investigations included control subjects who were followed for a similar length of as the gestation or postpartum period. Thus, multicenter controlled large scale prospective studies are urgently needed to clarify whether pregnancy and puerperium are related to an elevated risk for new-onset of OCD. These studies will also contribute to advances in the pathogenesis and treatment of OCD.

\section{RISK FACTORS}

We could not find any study analysing risk factors for pregnancy-induced OCD. The current data are based on relatively small sample sizes of the retrospective studies or case reports. In a relatively larger study, Neziroglu et al. (13) noted that of 23 patients who had onset of OCD during gestation, 12 (52.2\%) experienced onset with the first child, 8 (34.8\%) with the second child, and 3 (13.0) with the third child. Other publications report an onset during the first gestation in 7 of 10 cases of pregnancyassociated OCD. According to these limited reports, $50-80 \%$ of women with pregnancy-associated OCD were primigravidae $(16,25,46,47,50,53)$.

Studies describing the relationship between the initiation of OCD and gestational time suggest that OCD mostly occurs during the second or the third trimester of the gestation $(16,25,46,50)$. Finally, one study noted that there were no significant differences between pregnant women with and without OCD with regard to demographic characteristics, number of gestations and live births, gestational week, history of abortion, and the existence of gestational complications. A positive family history of OCD was significantly higher in pregnant women with OCD to those compared to without OCD. However, the sample of this study mostly comprised of women who had OCD before their gestation (25).

When compared to pregnancy-onset OCD, the studies 
Table 1: Factors associated with postpartum-onset obsessivecompulsive disorder

Primiparity

The first 4 weeks of postnatal period

Obsessive-compulsive personality disorder

Avoidant personality disorder

Personal history of major depression

The existence of OCD-related dysfunctional beliefs

described above illustrate more detailed infromation about the factors associated with postpartum-onset OCD. Table 1 shows several risk factors for the development of OCD in puerperium on the basis of published reports. OCD occurs after the first childbirth in $75-100 \%$ of the cases and within the first 4 weeks of postnatal period in almost all of the cases $(14,51,53)$. There is only one prospective study on this topic. The study suggests that the incidence of OCD was significantly higher in primiparous women than multiparous ones $(6.57 \%$ vs $1.81 \%)$. Nonetheless, this factor was not an independent predictor for postpartum-onset OCD (51). Similarly, in the study reported by Labad et al. (46), although all the women with postpartum-onset OCD were primiparous, primiparity was not significantly related to the onset or worsening in OCD symptoms during the puerperium. Probably these contradictions result from the small sample sizes (a total of 15) including women with postpartum-onset in these two studies. Briefly, primiparity seems to be a risk factor for postpartum-onset OCD. However, this is not clear from the results of statistical analyses in these two studies.

The first 4 weeks after the childbirth appear to be the most significant risk period in the postpartum stage for the occurence of OCD. The reports suggest that postpartum-onset OCD mostly begin within the first 4 weeks following delivery $(14,46,51)$. In an early retrospective study, Maina et al. (53), found that women with new-onset OCD during puerperium and those without a relationship between OCD and childbirth had similar lifetime psychiatric comorbidity and a positive familial history for OCD and other Axis I disorders. In contrast, more recently, Labad et al. (46) reported an association between postpartum-onset or worsening of OCD and personal history of major depression and premenstruel depressive mood .

Contrary to an early retrospective study reporting the frequency of pregnancy-related complications, surgical delivery, pre-term or post-term delivery in $25-62.5 \%$ of 8 women with postpartum-onset OCD (53), further prospective and retrospective studies indicated that sociodemographic characteristics and obstetric variables (e.g., type of delivery, history of abortion, pregnancy or delivery complications, numbers of children, and gender of baby) were unrelated to new-onset OCD in the puerperium (46,51). Most recently, Zambaldi et al. (33) found that a personal history, in the postnatal period, of previous psychiatric disorders, somatic disease or obstetric complications and multiparity were more prevalent in women with OCD compared to those without OCD. However, this study, which the OCD sample mostly included women with the disorder onset before the delivery, did not assess associated factors with postpartum-onset OCD.

Personality disorders and cognitively dysfunctional beliefs may also be risk factors for OCD. Avoidant and obsessive-compulsive personality disorders, which are two of the most common comorbid Axis II diagnoses in OCD $(54,56,57)$, independently predicted postpartumonset OCD in a prospective study (51). Additionally, two recent studies suggest that normal intrusions in the early postpartum period and OCD-related dysfunctional beliefs prospectively predicted postpartum-onset obsessive-compulsive symptoms $(36,37)$. Dysfunctional beliefs and personality factors may play a role in the development of obsessive-compulsive symptoms from normal intrusive thoughts by negatively influencing new mothers' strategies of coping with these thoughts $(37,51)$.

The main limitation of the present data is insufficiency of prospective studies, particularly about pregnancyonset OCD. The methodology and resarched variables in the studies are heterogenous. The risk factors described in Table 1 should be replicated in further studies. Additionally, to date, the possible effects of stressful life events, degree of social support, and quality of life were not explored in the studies.

\section{CLINICAL FEATURES}

Although early reports revealed that the most common obsessions were aggressive, which are seen in all patients, in postpartum women with OCD $(53,55)$, these findings were not confirmed with further studies. In a crosssectional study (33) of 400 postpartum women, aggressive 
and contamination obsessions were equally frequent (77.8\% for each) in OCD patients. Authors in this study also noted that the aggressive obsessions had 9 times more chances of occuring in a postpartum woman with OCD than in a healthy postpartum woman. Recently, a retrospective research has suggested that contamination/ cleaning symptoms were most likely related to a perinatal onset of OCD (48). Similarly, Forray et al. (49) noted that the perinatal-related OCD group was more likely to report contamination obsessions than the non perinatal-related OCD group. According to a prospective study, the most common obsessions in postpartum-onset OCD were contamination and those women also had a higher rate of aggressive obsessions than women without postpartumonset OCD (51). Likewise, Maina et al. (53) found that aggressive obsessions were more frequent in postpartumonset OCD than in non-postpartum-onset OCD.

To summarize, compared with non-postpartumonset OCD, aggressive obsessions exhibit a tendency to be seen more frequently seen in postpartum-onset OCD, and the most common obsessions were contamination and aggressive obsessions.

Another notable point regarding the clinical features is the content of the obsessions. Reports in the literature indicate that aggressive obsessions mostly include fear of harming the infant (e.g., dropping, throwing, violent horrific images and suffocation) $(15,33,35,51,55)$. Similarly, some contamination obsessions are focused on the baby (e.g., microorganisms, chemicals or dirt contaminations via her hand or the baby's bottles or foods) $(16,31,33,46)$. On the other hand, infant related obsessions especially aggressive thoughts, do not appear to be specific to postpartum-onset OCD (58). Depressed mothers have more frequently thoughts of harming their infant than non-depressed mothers (59). Wisner et al. (60) found that women with postpartum-onset major depression were morelikley to have aggressive obsessional thoughts compared to women with non-postpartumonset major depression. In this study, the most frequent content of the aggressive obsessions for those women with postpartum-onset major depression was causing harm to their newborns. Recently, a study have suggested positive correlations between postpartum depression and anxiety and frequency and intensity of child harming thoughts (61). Moreover, several studies have shown that majority of new mothers experience distressing intrusive thoughts about harming their infant $(37,62,63)$, while clinically significant OCD symptoms were rare (37).

Compared with obsessions, the research has less frequently focused on compulsive symptoms after the childbirth. The most prevalent compulsions were cleaning/washing (14-75\%) and checking (57-69\%) $(33,51,53,55)$. Secondary to obsessions, some compulsions were related to the baby, such as avoiding kitchen knives, not bathing the infant, staying physically isolated from them, checking the breathing or body of the baby and excessive or ritualized washing or cleaning $(15,33,46)$.

Women with postpartum-onset OCD have relatively good insight, and do not exhibit psychotic features $(15,51)$. According to a prospective study (51), the severity of the symptoms was lower in postpartum-onset OCD than non-postpartum-onset. Nonetheless, this comparison has some limitations. For example, the comparative sample with non-postpartum OCD includes patients who sought psychiatric care at a Psychiatry Outpatient Clinic.

Less attention has been focused on the clinical characteristics of OCD in pregnancy. Few reports suggest that contamination obsessions and cleaning/washing compulsions may be seen more frequently compared to other symptoms $(25,35,50)$. Additionally, symmetry obsessions and checking compulsions are frequently observed in pregnancy (26). Aggressive and contamination obsessions in some pregnant subjects may be related to the fetus $(25,28)$. Moreover, similar to postpartum women, some pregnant women experience thoughts of harming their unborn child (64). Overall, there is no significant difference between pregnant and non-pregnant OCD with regard to obsessive-compulsive symptoms (25).

\section{COURSE}

The severity of pre-existing OCD symptoms lessens or remains unchanged in a considerable proportion of women during their courses. The rates of worsening and improvement of OCD symptoms have been reported as $8-46 \%$ and $10-23 \%$, respectively. On the other hand, $31 \%$ to $69 \%$ of the women do not experince a significant change in the severity of the symptoms $(25,46,48,49,65,66)$. Recently, a cross-sectional study has suggested that individual histroy of major depression, the existence of major depression and anxiety disorders at the onset of 
pregnancy, contamination and symmetry/exactness obsessions, and cleaning/washing and ordering/ arranging compulsions were associated with worsening in pre-existing OCD symptoms during pregnancy (65). These findings may play a role in planning the treatment of OCD during pregnancy. Nevertheless, the available studies in the literature are retrospective in nature and based on the patients' recall. To date, there is no published study based on prospective observation regarding OCD using an objective and reliable instrument in this period.

Three retrospective studies suggest that during the postnatal period, pre-existing OCD symptoms worsened in $29-50 \%$ of the patients, whereas the symptoms decreased in $10 \%$ of the women. The severity of the symptoms was similar before and after the childbirth in $42 \%$ of women $(46,48,66)$. A prospective study with small sample size suggested that the intensity of OCD symptoms was greater in postpartum period than during pregnancy (26). Inconsistently, results from 16 patients prospectively observed suggest that the severity of obsessions significantly decreases from 38th gestational week to 6 weeks postnatally. The authors also noted an ameloration of the symptoms in at least $25 \%-50 \%$ of the patients. The main two limitations of this study are small sample size and the short follow-up period (67). On the other hand, there is a case report supporting a decrease in OCD symptoms in puerperium (50).

The course of pregnancy-onset OCD is unknown, although it is reported a decrease in the symptoms in 3 of 4 women after the childbirth has been reported $(50,67)$. According to a larger case series (68), postpartum-onset OCD persisted in most women (88.9\%) for the duration of one-year, when they were not treated.

As a result, it is unclear whether pregnancy- and postpartum-onset OCD are transient or persistent, but it is considered that postpartum-onset OCD tends to become chronic. However, this opinion should be confirmed by further large-scale longitudinal studies. These studies should also comprise other factors related to the course of OCD during the periods of pregnancy and puerperium.

\section{COMORBIDITY}

Case series reported in the literature state at least one comorbid psychiatric disorder in $100 \%$ and major depression in $60 \%$ of women with postpartum-onset OCD. Comorbid depression developed simultaneously or within or 2 to 3 weeks after the onset of OCD $(14,55)$. Recently, the proportion of disorders accompanying OCD has been reported to be $42.9 \%$ in the postnatal period (32). In cross-sectional clinical investigations, the rate of depression in women with OCD in this period was $25-38.9 \%(31,33)$. In additon, retrospective studies revealed that $24-35 \%$ of OCD women who delivered a child experienced a postpartum depression $(46,47)$. Depression was not only frequently observed but also it seems to be associated with postpartum exacerbation of OCD $(46,66)$.

There are no studies in the reported literature examining comorbid disorders in pregnant women with OCD. Moreover, the available infromation on comorbid conditions in postpartum-onset OCD is based on case series. Although there are several retrospective or crosssectional studies, these note comorbidity in postpartum women with OCD to be without any distinction from OCD with onset before or after the childbirth. Finally, there is no data about comorbid disorders except depression.

\section{CONCLUSION}

In recent years, while there have been more published data on the topic, the number of studies is still inadequate. Furthermore, the studies to date have significant limitations and methodological heterogeneity, with a considerable number comprising retrospective reports or case series. Most of the cross-sectional studies do not include a control group. Prospective or prospectivecontrolled studies are very inadequate. Therefore, definitive answers to the questions that were put forth in the introduction are difficult.

The prevalence and incidence of OCD during pregnancy and the postpartum period are usually reported relatively more frequently in the investigations when compared to its clinical caharacteristics, risk factors, comorbidity, and course in these periods. For example, data on course of OCD were obtained from mostly retrospective studies based on subjective recall of OCD patients who were admitted to an outpatient clinic in relation to onset, types, severity and course of obsessivecompulsive symptoms. The course of OCD during pregnancy has not been explored by any prospective 
study yet.

Despite the limitations of available studies, the review suggests the following: 1) OCD is not rare in pregnancy and the postpartum period. 2) Pregnant and postpartum women exhibit an elevated vulnerability to new-onset of OCD. 3) Postpartum-onset OCD has relatively similar clinical characteristics to non-postpartum-onset OCD,

\section{References:}

1. Bijl R.V, Ravelli A, van Zessen G. Prevalence of psychiatric disorder in the general population: results of the Netherlands Mental Health Survey and Incidence Study (NEMESIS). Social Psychiatry Psychiatr Epidemiol. 1998; 33:587-595.

2. Cho M.J, Kim J.K, Jeon H.J, Suh, T, Chung, I.W, Hong, J.P. et al. Lifetime and 12-month prevalence of DSM-IV psychiatric disorders among Korean adults. J Nerv Ment Dis. 2007; 195:203210.

3. Vicente B, Kohn R, Rioseco P, Saldivia S, Levav I, \& Torres S Lifetime and 12-month prevalence of DSM-III-R disorders in the Chile Psychiatric Prevalence Study. Am J Psychiatry. 2006; 163:1362-1370.

4. Canino G.J, Bird H.R, Shrout P.E. et al. The prevalence of spesific psychiatric disorders in Puerto Rico. Arch Gen Psychiatry. 1987; 44:727-735.

5. Kessler R.C, Berglund P, Demler O, Jim R, Merikangas KR, Walters E.E. Lifetime prevalence and age-of-onset distributions of DSM-IV disorders in the National Comorbidity Survey Replication. Arc Gen Psychiatry. 2005; 62:593-602.

6. Karno M, Golding J.M, Sorenson S.B, Burnam A. The epidemiology of obsessive-compulsive disorder in five US communities. Arch Gen Psychiatry. 1988; 45:1094-1099.

7. Huppert J.D, Simpson H.B, Nissenson K.J, Liebowitz M.R, Foa E.B Quality of life and functional impairment in obsessive-compulsive disorder: A comparison of patients with and without comorbidity, patients in remission, and healthy controls. Depress Anxiety. 2009; 26: $39-45$.

8. Kıvırcık Akdede B.B, Alptekin K, Akvardar Y, Kitis A. . Quality of life in patients with obsessive-compulsive disorder: Relations with cognitive functions and clinical symptoms. Turk Psikiyatri Derg. 2005; 16:13-19.

9. Bobes J, González M.P, Bascarán M.T, Arango C, Sáiz P.A, Bousoño M. Quality of life and disability in patients with obsessivecompulsive disorder. Eur Psychiatry. 2001; 16:239-245.

10. Weissman M.M, Bland R.C, Canino G.J, Greenwald S, Hwu H.G, Lee C.K. et al. The cross national epidemiology of obsessive kompulsive disorder. J Clin Psychiatry. 1994; 55:5-10.

11. Çilli A.S, Telcioğlu M, Aşkın R, Kaya N, Bodur S, Kucur R. Twelvemonth prevalence of obsessive-compulsive disorder in Konya, Turkey. Compr Psychiatry. 2004; 45:367-374.

12. Burke K.C, Burke J.D, Regier D.A, Rae D.S. Age at onset of selected mental disorders in five community populations. Arch Gen Psychiatry. 1990; 47:511-518. except aggressive obsessions which are more frequently seen in postpartum-onset OCD. 4) The severity of OCD symptoms decreases or remains unchanged in a considerable percentage of pregnant or puerperal women. However, these suggestions should be confirmed by results of further prospective or cross-sectional controlled studies with larger sample sizes.

13. Neziroglu F, Anemone R, Yaryura-Tobias J.A. Onset of obsessivecompulsive disorder in pregnancy. Am J Psychiatry. 1992; 149:947950.

14. Sichel D.A, Cohen L.S, Dimmock J.A, Rosenbaum J.F. Postpartum obsessive-compulsive disorder: a case series. J Clin Psychiatry. 1993; 54156-159.

15. Sichel D, Cohen L.S, Rosenbaum J.F, Driscoll J. Postpartum-onset obsessive-compulsive disorder. J Clin Psychiatry. 1993; 34:277279.

16. Hertzberg T, Leo R.J, Kim K.Y. Recurrent obsessivecompulsive disorder associated with pregnancy and childbirth Psychosomatics. 1997; 38:386-388.

17. Chelmow D, Halfin V.P. Pregnancy complicated by obsessivecompulsive disorder. J Matern Fetal Med. 1997; 6:31-34.

18. Andersson L, Sundström-Poromaa I, Bixo M, Wulff M, Bondestam $\mathrm{K}$, Åström M. Point prevalence of psychiatric disorders during the second trimester of pregnancy: A population-based study. Am J Obstet Gynecol, 2003; 189:148-154.

19. Andersson L, Sundström-Poromaa I, Wulff M, Åström M, Bixo M. Depression and anxiety disorder during pregnancy and six months postpartum: a follow-up study. Acta Obstet Gynecol Scand. 2006; 85:937-944.

20. Zar M, Wijma K, Wijma B. Relations between anxiety disorders and fear of childbirth during late pregnancy. Clin Psychol Psychother. 2002; 9:122-130.

21. Sutter-Dallay A.L, Giaconne-Marcesche V, Glatigny-Dallay E, Verdeoux H. Women with anxiety disorders during pregnancy are at increased risk of intense postnatal depressive symptoms: a prospective survey of the MATQUID cohort. Eur Psychiatry. 2004; 19:459-463.

22. Adewuya A.O, Ola B.A, Aloba O.O, Mapayi B.M. Anxiety disorders among Nigerian women in late pregnancy: a controlled study. Arch Womens Ment Health. 2006; 9:325-328.

23. Felice E, Saliba J, Grech, V, Cox J, Calleja N. Antenatal psychiatric morbidity in Maltase women. Gen Hosp Psychiatry. 2007; 29:501505 .

24. Borri, C., Mauri, M., Oppo, A., Banti, S., Rambelli, C., Ramacciotti, D., et al. (2008). Axis I psychopathology and functional impairment at the third month of pregnancy: results from the Perinatal Depression-Research and Screening Unit (PND-ReScU) Study. J Clin Psychiatry. 2008; 69:1617-1624. 
25. Uguz F, Gezginc K, Zeytinci I.E, Karatayli S, Karatayli R, Aksin R, Guler O, Gecici O. Obsessive-compulsive disorder in pregnant women during the third trimester of pregnancy. Compr Psychiatry. 2007; 48:441-445.

26. Chaudron L.H, Nirodi N. The obsessive-compulsive spectrum in the perinatal period: a prospective pilot study. Arch Womens Ment Health. 2010; 13:403-410.

27. Fontenelle L.F, Mendlowicz MV, Versiani M. The descriptive epidemiology of obsessive-compulsive disorder. Progress Neuropsychopharmacol Biol Psychiatry. 2006; 30:327-337.

28. Brockington I.F, Macdonald E, Wainscott G. Anxiety, obsessions and morbid preoccupations in pregnancy and puerperium. Arch Womens Ment Health. 2006; 9:253-263.

29. Faisal-Cury A, Menezes P, Araya R, Zugaib M. Common mental disorders during pregnancy: prevalence and associated factros among low-income women in São Paulo, Brazil. Arch Womens Ment Health. 2009; 12:335-339.

30. Wenzel A, Haugen E.N, Jackson L.C, Brendle J.R. Anxiety symptoms and disorders at eight weeks postpartum. J Anxiety Disord. 2005; 19:295-311.

31. Wenzel A, Gorman L.L, O'Hara M.W, Stuart S. The occurence of panic and obsessive-compulsive symptoms in women with postpartum dsyphoria: a prospective study. Arch Womens Ment Health. 2001; 4:5-12.

32. Navarro P, Garcia-Esteve L, Ascaso C, Aguado J, Gelabert E, Martin-Santos R. Non-psychotic psychiatric disorders after childbirth: Prevalence and comorbidity in a community sample. J Affect Disord. 2008; 109:171-176.

33. Zambaldi C.F, Cantilino A, Montenegro A.C, Paes J.A, de Albuquerque T.L, Sougey E.B. Postpartum obsessive-compulsive disorder: prevalence and clinical characteristics. Compr Psychiatry. 2009; 50:503-509.

34. Abramowitz J.S, Schwartz S.A, Moore K.M. Obsessional thouhts in postpartum females and their partners: content, severity, and relationship with depression. J Clin Psychol Med Settings. 2003; 10:157-164.

35. Abramowitz J.S, Schwartz S.A, Moore K.M, Luenzmann K.R. Obsessive-compulsive symptoms in pregnancy and the puerperium: A review of the literature. J Anxiety Disord. 2003; 17:461-478.

36. Abramowitz J.S, Nelson C.A, Rygwall R, Khandker M. The cognitive mediation of obsessive-compulsive symptoms: A longitidunal study. J Anxiety Disord. 2007; 21:91-104.

37. Abramowitz J.S, Khandker M, Nelson C.A, Deacon B.J, Rygwall $\mathrm{R}$. The role of cognitive factors in pathogenesis of obsessivecompulsive symptoms: A prospective study. Behav Res Ther. 2006; 44: $361-1374$

38. Andrade L, Walters E.E, Gentil V, Laurenti R. Prevalence of ICD10 mental disorders in a cathcment area in the city of São Paulo, Brazil. Soc Psychiatry Psychiatr Epidemiol. 2002; 37:316-325.

39. Vicente B, Kohn R, Rioseco P, Saldivia S, Baker C, Torres S. Population prevalence of psychiatric disorders in Chile: 6-month and 1-month rates. Br J Psychiatry. 2004; 84:299-305.

40. Faravelli C, Degl'Innocenti B.G, Giardinelli L. Epidemiology of anxiety disorders in Florence. Acta Psychiatr Scand. 1989; 79:308-312.
41. Faravelli C, Abrardi L, Bartolozzi D, Cecchi C, Cosci F, D’Adamo D, et al. The Sesto Fiorentino Study: Point and one-year prevalences of psychiatric disorders in an Italian community sample using clinical interviewers. Psychother Psychosomatics. 2004; 73:226-234.

42. Gureje O, Lasebikan V.O, Kola L, \& Makanjuola V.A. Lifetime and 12-month prevalence of mental disorders in the Nigerian Survey of Mental Health and well-being. Br J Psychiatry. 2006; 188:465-471.

43. Uguz F, Gezginc K, Kayhan F, Sarı S, Büyüköz D. Is pregnancy associated with mood and anxiety disorders? A cross-sectional study. Gen Hosp Psychiatry. 2010; 32:213-215.

44. Vesga-López O, Blanco C, Keyes K, Olfson M, Grant B.F, Hasin D. Psychiatric disorders in pregnant and postpartum women in United States. Arch Gen Psychiatry. 2008; 65: 805-815.

45. Kitamura T, Yoshida K, Okano T, Kinoshita K, Hayashi M, Toyoda $\mathrm{N}$, et al. Multicentre prospective study of perinatal depression in Japan: incidence and correlates of antenatal and postnatal depression. Arch Womens Ment Health. 2006; 9:121-130.

46. Labad J, Menchón J.M, Alonso P, Segalàs C, Jiménez S, Vallejo J. Female reproductive cycle and obsessive-compulsive disorder. J Clin Psychiatry. 2005; 66:428-435.

47. Williams K.E, Koran L.M. Obsessive-compulsive disorder in pregnancy, the puerperium, and the prementruum. J Clin Psychiatry. 1997; 58: 330-334.

48. Labad J, Alonso P, Segalas C, Reval E, Jimenez S, Bueno B, et al Distinct correlates of hoarding and cleaning symptom dimensions in relation to onset of obsessive-compulsive disorder at menarche or perinatal period. Arch Womens Ment Health. 2010; 13:75-81.

49. Forray A, Focseneanu M, Pittman B, McDougle C.J, Epperson C.N. Onset and exacerbation of obsessive-compulsive disorder in pregnancy and the postpartum period. J Clin Psychaitry. 2010; 71:1061-1068.

50. Kalra H, Tandon R, Trivedi J.K, Janca A. Pregnancy-induced obsessive-compulsive disorder: a case report. Ann Gen Psychiatry. 2005;4: 12.

51. Uguz F, Akman C, Kaya N, Cilli A.S. Postpartum-onset obsessivecompulsive disorder: Incidence, clinical features, and related factors. J Clin Psychiatry. 2007; 68: 132-138.

52. Mirsi S, Milis L. Obsessive-compulsive disorder in the postpartum. Open-label trial of quetiapine augmentation. J Clin Psychopharmacol. 2004; 24:624-627.

53. Maina G, Albert U, Bogetto F, Vaschetto P, Ravizza L. et al. Recent life events and obsessive-compulsive disorder (OCD): the role of pregnancy delivery. Psychiatry Res. 1999; 89:49-58.

54. Matsunaga H, Kiriike N, Miyata A, Iwasaki Y, Matsui T, Nagata T, Takei Y, Yamagami S. Personality disorders in patients with obsessive-compulsive disorder in Japan. Acta Psychiatr Scand. 1998; 98:128-134.

55. Arnold L.M. A case series of women with postpartum-onset obsessive-compulsive disorder. Primary Care Companion J Clin Psychiatry. 1999; 1:103-108.

56. Samuels J, Nestadt G, Bienvenu J, Costa P.T, Riddle M.A, Liang K.Y, Hoehn-Saric R, Cullen B.A. Personality disorder and normal personality dimensions in obsessive-compulsive disorder. $\mathrm{Br} \mathrm{J}$ Pychiatry. 2000; 177:457-462. 
57. Bejerot S, Ekselius L, von Knorring L. Comorbidity between obsessive-compulsive disorder (OCD) and personality disorders. Acta Psychiatr Scand. 1998; 97:398-402.

58. Ross L.E, McLean L.M. Anxiety disorders during pregnancy and the postpartum period: A systematic review. J Clin Psychiatry. 2006; 67:1285-1298.

59. Jennings K.D, Ross S, Popper S, Elmore M. Thoughts of harming infants in depressed and nondepressed mothers. J Affect Disord. 1999; 54 21-28.

60. Wisner K.L, Peindl K.S, Gigliotti T, Hanusa B.H. Obsessions and compulsions in women with postpartum depression. J Clin Psychiatry. 1997; 60 176-180.

61. Humenik A.L, Fingerhut R. A pilot study assessing the relationship between child harming thoughts and postpartum depression. J Clin Psychol Med Settings. 2007; 14:360-366.

62. Fairbrother N, Woody S.R. New mothers' thoughts of harm related to the newborn. Arch Womens Ment Health. 2008; 11:221-229.

63. Abramowitz J.S, Meltzer-Brody S, Leserman J, Killenberg S, Rinaldi K, Mahaffey B.L, Pedersen C. Obsessional thoughts and compulsive behaviors in a sample of women with postpartum mood symptoms. Arch Womens Ment Health. 2010; 13:523-530.
64. Leckman J.F, Mayes L.C, Feldman R, Evans D.W, King R.A, Cohen D.J. Early parental preoccupations and behaviors and their possible relationship to the symptoms of obsessive-compulsive disorder. Acta Psychiatr Scand, 1999; 100:1-26.

65. Uguz F, Kaya V, Gezginc K, Kayhan F, Çiçek E. Clinical correlates worsening in obsessive-compulsive symptoms during pregnancy. Gen Hosp Psychiatry. 2011; 33:197-99.

66. Vulink N.C, Denys D, Bus L, Westenberg H.G. Female hormones affect symptom severity in obsessive-compulsive disorder. Int Clin Psychopharmacol, 2006; 21:171-175.

67. Uguz F, Gezginc K, Zeytinci I.E, Karatayli S, Karatayli R, Askin $\mathrm{R}$, Guler O, Gecici O. Course of obsessive-compulsive disorder during early postpartum period: a prospective analysis of 16 cases. Compr Psychiatry. 2007; 48:558-561.

68. Uguz F, Kaya N, Sahingoz M, Cilli A.S, Akman C. One year followup of postpartum-onset obsessive-compulsive disorder: A case series. Progress Neuro--Ppsychopharmacol Biol Psychiatry. 2008; 32:1091-1092. 